Article

\title{
Black-Si as a Photoelectrode
}

\author{
Denver P. Linklater ${ }^{1,2,3, *(0)}$, Fatima Haydous ${ }^{4,+}$, Cheng $\mathrm{Xi}^{4}$, Daniele Pergolesi ${ }^{4}$, Jingwen $\mathrm{Hu}^{3}$, \\ Elena P. Ivanova ${ }^{1}\left(\mathbb{D}\right.$, Saulius Juodkazis ${ }^{3,5}{ }^{(}$, Thomas Lippert ${ }^{4, *}$ and Jurga Juodkazyte ${ }^{6, *}(\mathbb{C}$ \\ 1 School of Science, RMIT University, Melbourne, VIC 3000, Australia; elena.ivanova@rmit.edu.au \\ 2 Melbourne Centre for Nanofabrication, ANFF, 151 Wellington Road, Clayton, VIC 3168, Australia \\ 3 Optical Sciences Centre and ARC Training Centre in Surface Engineering for Advanced Materials (SEAM), \\ School of Science, Swinburne University of Technology, Hawthorn, VIC 3122, Australia; \\ jhu@swin.edu.au (J.H.); sjuodkazis@swin.edu.au (S.J.) \\ 4 Laboratory for Multiscale Materials Experiments, Paul Scherrer Institut, Villigen PSI, CH-5232 Villigen, \\ Switzerland; haydous@kth.se (F.H.); xi.cheng@psi.ch (C.X.); Daniele.Pergolesi@psi.ch (D.P.) \\ 5 Tokyo Tech World Research Hub Initiative (WRHI), School of Materials and Chemical Technology, \\ Tokyo Institute of Technology, 2-12-1, Ookayama, Meguro-ku, Tokyo 152-8550, Japan \\ 6 Center for Physical Sciences and Technology, Saulètekio ave. 3, LT-10257 Vilnius, Lithuania \\ * Correspondence: denver.linklater@rmit.edu.au (D.P.L.); Thomas.Lippert@psi.ch (T.L.); \\ jurga.juodkazyte@ftmc.lt (J.J.) \\ + Current address: Division of Applied Physical Chemistry, KTH Royal Institute of Technology, \\ Teknikringen 30, SE-114 28 Stockholm, Sweden.
}

Received: 30 March 2020; Accepted: 20 April 2020; Published: 1 May 2020

\begin{abstract}
The fabrication and characterization of photoanodes based on black-Si (b-Si) are presented using a photoelectrochemical cell in $\mathrm{NaOH}$ solution. B-Si was fabricated by maskless dry plasma etching and was conformally coated by tens-of-nm of $\mathrm{TiO}_{2}$ using atomic layer deposition (ALD) with a top layer of $\mathrm{CoO}_{x}$ cocatalyst deposited by pulsed laser deposition (PLD). Low reflectivity $R<5 \%$ of b-Si over the entire visible and near-IR $(\lambda<2 \mu \mathrm{m})$ spectral range was favorable for the better absorption of light, while an increased surface area facilitated larger current densities. The photoelectrochemical performance of the heterostructured b-Si photoanode is discussed in terms of the n-n junction between b-Si and $\mathrm{TiO}_{2}$.
\end{abstract}

Keywords: black-Si; antireflection; photoanode; water splitting

\section{Introduction}

The nanotexturing of silicon $(\mathrm{Si})$ to endow the surface topography with a random array of high-aspect-ratio spikes that can efficiently trap light (enhancing absorption, since reflection is suppressed) due to a gradual refractive index change - known as b-Si [1] —has demonstrated a wide range of useful properties: b-Si acts as an anti-reflection surface over the VIS-IR spectral range, exhibits efficient bactericidal activity towards gram-positive and gram-negative bacteria [2] (Figure 1a), can rupture the soft membranes of red blood cells [3], acts as a field emitter electrode [4], can be used as a substrate for surface enhanced Raman sensing/spectroscopy (SERS) [5], and has application in solar cell technology [6,7]. Additionally, the optical binding/trapping of small particles on b-Si was recently demonstrated at very high laser powers when the nonlinear optical effects inside the trapped material could be induced [8]. Furthermore, the high thermal conductivity of b-Si, due to its crystalline nature, is a useful property in heat dissipation aided by the large surface area of b-Si. This wide range of applications are enabled by the specific physico-chemical properties of the nanostructured Si surface.

There is increasing interest to use b-Si as a photoelectrode in the photelectrochemical (PEC) splitting of water as both a photoanode and photocathode. Nanoporous p-type b-Si with a hybrid 
organic/inorganic interfacial architecture, consisting of an organic molecular monolayer beneath ALD deposited $\mathrm{TiO}_{2}$ modified with $\mathrm{Pt}$ nanoparticles (NPs), was recently studied as a photocathode [9]. The critical importance of the careful consideration of the semiconductor junction engineering was pinpointed. Yang et al. (2019) introduced a dual protection layer strategy where the first layer of $\mathrm{TiO}_{2}$ was deposited on p-type nanoporous b-Si, while the second layer was deposited on top of the hydrogen evolution reaction (HER) co-catalyst [10]. Significant improvement in the durability of b-Si photocathodes in both acid and alkaline medium was demonstrated. Contrary to these results, Oh et al. (2019) reported that transition metal NPs electrodeposited directly onto n-type b-Si surfaces can stabilize photoanodes without the need for a protection layer [11]. However, the role of the protective layer in their study was, in fact, played by thermally grown $\mathrm{SiO}_{x}$. Recently, b-Si demonstrated enhanced photoelectrochemical efficiency and stability using a conformal $\mathrm{TiO}_{2}$ film on a nanoporous n-type silicon photoanode [12]. This b-Si/ $\mathrm{TiO}_{2} / \mathrm{Co}(\mathrm{OH})_{2}$ nanostructured photoelectrode produced a saturated photocurrent density of $32.3 \mathrm{~mA} \mathrm{~cm}^{-2}$ at an external potential of $1.48 \mathrm{~V}$ versus reference electrode (RHE) in $1 \mathrm{M} \mathrm{NaOH}$ electrolyte under 1 Sun illumination. The authors demonstrated that an amorphous ALD $\mathrm{TiO}_{2}$ layer was able to passivate defective surface sites and increase the efficiency of electron-hole separation as well as the lifetime of minority charge carriers in n-type b-Si PEC photoelectrodes.

Here, b-Si surfaces are assessed for their photoelectrochemical (PEC) performance by exploring the influence of surface spike topography (height/pitch) and $\mathrm{TiO}_{2}$ film thickness. A layer of $\mathrm{CoO}_{x}$ as oxygen evolution reaction (OER) cocatalyst is explored to enhance the photo-current output.
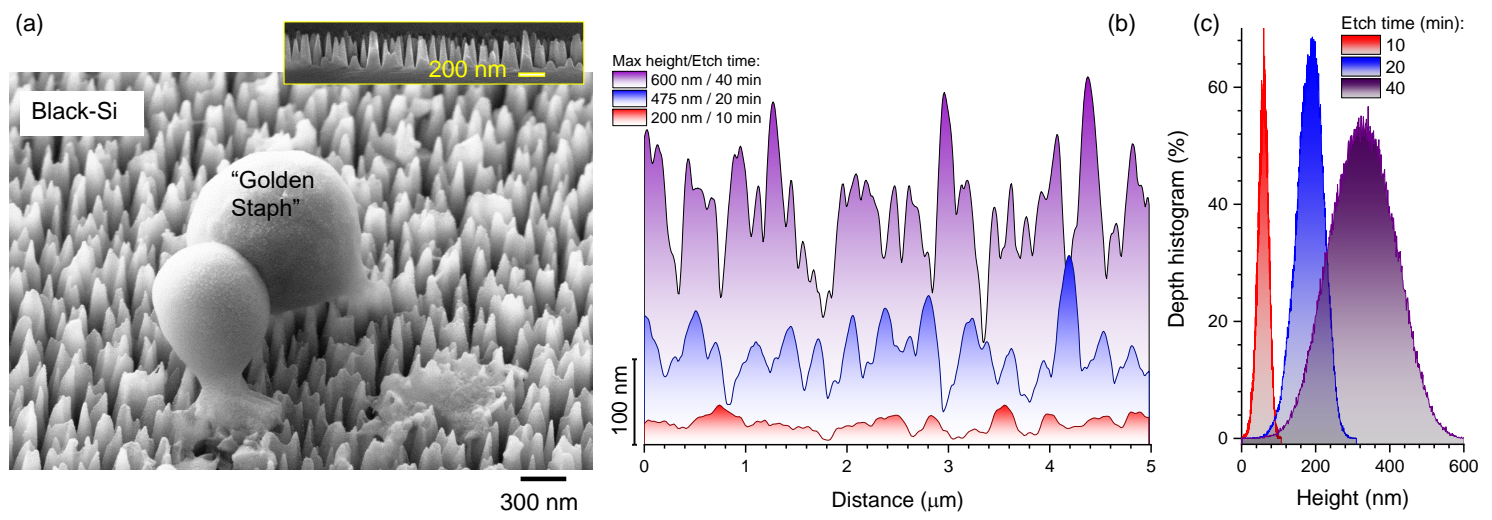

Figure 1. Mechanically bactericidal surface of b-Si. (a) Scanning electron microscope (SEM) image of a Gram-positive Staphylococcus aureus "Golden Staph" cell ruptured on b-Si. Inset SEM image shows the side profile of b-Si prepared by typical 20 min dry plasma etching with $\mathrm{SF}_{6}$ and $\mathrm{O}_{2}$ gases. (b) Height profiles of atomic force microscopy (AFM) cross sections for different plasma dry etching times of 10, 20, and $40 \mathrm{~min}$ (see Appendix for SEM micrographs). (c) Depth histogram: a depth (height) pixel distribution in the AFM image of b-Si etched for different times (see Appendix A for the bearing ratios and statistical analysis).

\section{Experimental}

\subsection{Fabrication of Photoanodes}

B-Si was fabricated using n-type As-doped $100 \mathrm{~mm}$ diameter silicon wafers with specific resistivity of $0.005 \Omega \cdot \mathrm{cm}$ and processed with a Samco RIE101iPH inductively coupled plasma (ICP) assisted reactive ion etching (RIE) tool. Si surfaces were initially cleaned with isopropanol and then dried under nitrogen gas flow to remove contaminants. Si wafers were then etched according to the following recipe: the etchant gases were $\mathrm{SF}_{6} / \mathrm{O}_{2}$ with respective flow rates of $35 / 45 \mathrm{sccm}$. The process pressure was $1 \mathrm{~Pa}$, ICP power of $150 \mathrm{~W}$, and RIE bias power of $15 \mathrm{~W}$. Etching time was varied between 10 and $40 \mathrm{~min}$ to produce high aspect ratio nanopillars of differing heights (Figures 1 and A2). During the etching process, 
the spontaneous passivation mask was not efficiently removed during alternating rounds of etching and deposition, therefore a simple $10 \mathrm{wt} \%$ sulfuric acid solution and sonication for $10 \mathrm{~min}$ was used to remove the contaminative mask. Figure 1 shows a typical surface pattern measured by scanning electron microscopy (SEM) and height profiles obtained by atomic force microscopy (AFM).

\section{2. $\mathrm{TiO}_{2}$ and $\mathrm{CoO}_{x}$ Cocatalyst Deposition}

$\mathrm{TiO}_{2}$ thin films of 10,25 , or $50 \mathrm{~nm}$ were deposited using atomic layer deposition (ALD) (Cambridge Nanotech ALD Fiji F200 \& Savannah s100). B-Si samples were used for the ALD coating without the removal of native oxide. Figure 2 shows SEM images and the X-ray photo-electron spectroscopy (XPS) characterization of the surfaces after $\mathrm{TiO}_{2}$ deposition. A cobalt oxide $\mathrm{CoO}_{x}$ cocatalyst layer was deposited using a pulsed laser deposition (PLD) setup based on a $248 \mathrm{~nm}$ wavelength $\mathrm{KrF}$ eximer laser [13]; PLD is a practical method to deposit materials from targets with complex composition at a fast deposition rate. The resultant surface morphology was inspected by SEM.

\subsection{PEC Measurements}

PEC measurements were performed in a three-electrode configuration in $0.5 \mathrm{M} \mathrm{NaOH}(\mathrm{pH} 13.0)$ aqueous solution. The b-Si photoelectrode was used as the working electrode. Silver paste was applied for the electrical connection between the sample and the clamped wire; an epoxy resin covered the contact and insulated it from the electrolyte. Epoxy resin was also used to insulate the back side and the edges of the b-Si sample to avoid an electrical short-circuit with only the front side of the sample exposed to the electrolyte and light. A coiled Pt wire and $\mathrm{Ag} / \mathrm{AgCl}$ were used as the counter and reference electrodes, respectively. To simplify the display of the working electrode potential, the potential versus reference hydrogen electrode (RHE), obtained according to the relation $\mathrm{E}(\mathrm{vs}$. $\mathrm{RHE})=\mathrm{E}(\mathrm{vs} . \mathrm{Ag} / \mathrm{AgCl})+0.197+0.059 \mathrm{pH}$, is adopted throughout this article A Solartron 1286 electrochemical interface was used to carry out the voltage scan and current collection. Potentiodynamic measurements with a scan rate of $10 \mathrm{mV} / \mathrm{s}$ in the potential window of $0.5-1.7 \mathrm{~V} \mathrm{RHE}$ were performed to investigate the PEC performance of $\mathrm{b}-\mathrm{Si}-\mathrm{TiO}_{2}$ multiphases. The chopped dark-light current densities were normalized according to the illuminated area. The light source was a $150 \mathrm{~W}$ Xe lamp equipped with an AM $1.5 \mathrm{G}$ filter $\left(100 \mathrm{~mW} / \mathrm{cm}^{2}\right.$, Newport 66477-150XF-R1) calibrated with a photodetector (Gentec-Electro Optics, Inc., Quebec City).
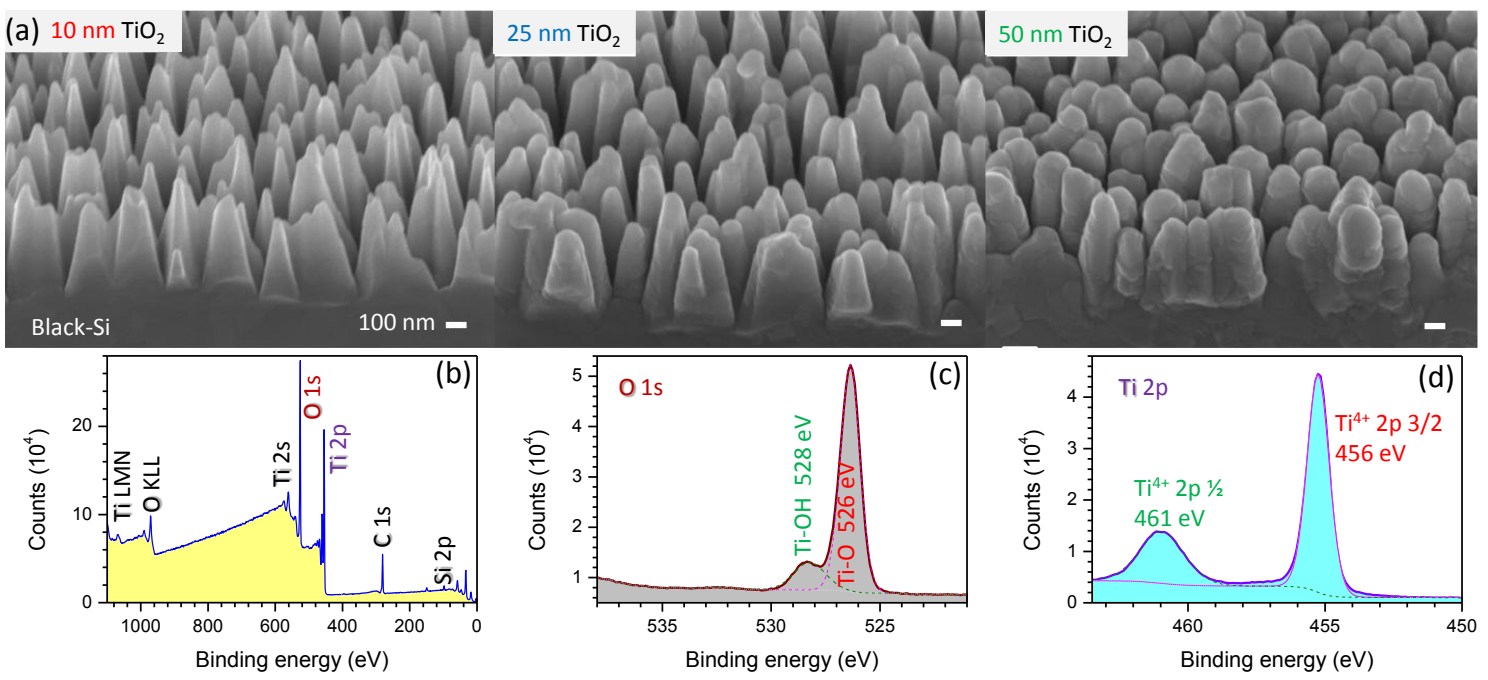

Figure 2. Surface characterization of b-Si photoelectrodes. (a) Side-view SEM images of b-Si coated with different thickness of $\mathrm{TiO}_{2}$ by atomic layer deposition (ALD). Scale bars $100 \mathrm{~nm}$. b-Si was etched for $40 \mathrm{~min}$. (b-d) XPS surface analysis for wide and narrow spectral windows at O1s and Ti2p bands from b-Si sample coated with $25 \mathrm{~nm}$ of $\mathrm{TiO}_{2}$. 


\section{Results and Discussion}

B-Si has antireflective properties across the entire visible spectrum range $[14,15]$ with a reflectivity of only a few percent $R<5 \%$ (Figure A2) after $20 \mathrm{~min}$ of plasma etching. Since Si can be either an $\mathrm{n}$-/p-type electrode it was interesting to explore application of b-Si as a photoelectrode with more efficient light absorption. Furthermore, an increase of the surface area, due to nanotexturing [16], is another advantage of considering $\mathrm{b}$-Si for a large current operation of photo-electrochemical cells. Complex pathways of (photo)electrochemical modification of Si are possible in acidic solutions, due to the different valence states of Si [17]. In basic solutions, Si is usually stable at room temperature [18], hence, is promising as an electrode. When metals or semiconductors are deposited over b-Si surfaces, a light scattering pattern that creates the de-polarization of light and the E-field component perpendicular to the electrode or catalyst surface can be formed and facilitate a charge (electron or hole) transport through the interface [19].

\subsection{Black-Si with $\mathrm{TiO}_{2}$ : Potentiostatic and Potentiodynamic Scans}

The potentiodynamic polarization curves recorded in the solution of $0.5 \mathrm{M} \mathrm{NaOH}$ under chopped illumination for b-Si electrodes fabricated using different etching times and coated with $\mathrm{TiO}_{2}$ layers of different thickness are compared in Figure 3. A slight increase in the magnitude of dark currents with increase in etching duration can be observed in Figure 3a-c. This can be attributed to the increase in the electrochemically active surface area of the electrode with etching time, which is consistent with the height profiles of AFM cross-sections shown in Figure 1b. Another observation is that the deposition of $\mathrm{TiO}_{2}$ on b-Si leads to an increase in photoanodic current. This is especially obvious in the case of b-Si samples with higher roughness, i.e., etched for 20 and $40 \mathrm{~min}$. The most significant effect of $\mathrm{TiO}_{2}$ on the photocurrent is observed when the $\mathrm{TiO}_{2}$ thickness is increased from $10 \mathrm{~nm}$ to $25 \mathrm{~nm}$, whereas a further thickening of the layer (up to $50 \mathrm{~nm}$ ) was not efficient in terms of the photoelectrochemical performance of the samples.
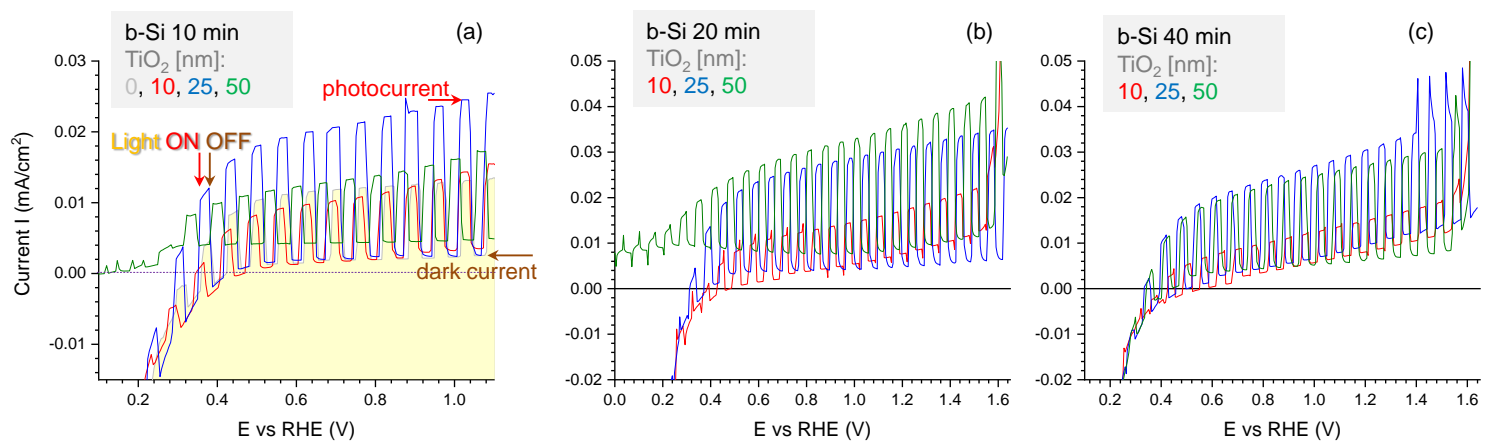

Figure 3. Potentiodynamic scans for the b-Si photoanodes fabricated for (a) 10, (b) 20 and (c) 40 min and coated with 10,25 , or $50 \mathrm{~nm} \mathrm{TiO}_{2}$, respectively, in $\mathrm{NaOH}$ electrolyte under chopped light illumination; $\mathrm{x}, \mathrm{y}$-scales are different for a better presentation.

The same regularities can be seen in chronoamperograms run under chopped illumination at the stationary potential of $1.23 \mathrm{~V}$ (Figure 4). The highest photocurrents (taken as the difference between the current values in the dark and under illumination) were observed in the case of b-Si samples etched for 20 min with $25 \mathrm{~nm}$ thick $\mathrm{TiO}_{2}$ layer (Figure $4 \mathrm{~b}$ ), which means that such fabrication conditions ensure the most efficient generation, separation, and transport of the charge carriers. To analyze these processes in more detail, an energy band diagram of n-n junction between n-type b-Si and n-type $\mathrm{TiO}_{2}$ has been constructed and is shown in Figure 5. These semiconductors form a type-I, or straddling gap, heterojunction. In accordance with their bandgap values, i.e., $3.1 \mathrm{eV}$ for $\mathrm{TiO}_{2}$ and $1.12 \mathrm{eV}$ for $\mathrm{Si}$, titania will absorb the UV portion of incident light, while silicon will absorb longer wavelengths. In the case of an n-type photoanode immersed in electrolyte solution under illumination (white light), photogenerated holes should be drifting to the semiconductor-electrolyte interface to participate in 
the oxidation of solution species (water molecules), whereas photoelectrons should be driven to the electrode bulk and towards the counter electrode to take part in the reduction reaction. Due to the upward band bending at the heterojunction between the two n-type semiconductors, an energy barrier is formed for the transport of photogenerated electrons from the conduction band of $\mathrm{TiO}_{2}$ to that of $\mathrm{Si}$ (Figure 5a) at no external bias conditions. The barrier for photoholes drifting from the valence band of $\mathrm{Si}$ to the valence band of $\mathrm{TiO}_{2}$ is even higher. The positive polarization of the electrode provides the energy required to overcome this barrier (Figure $5 b$ ) and this is the reason why the photocurrent increases with an increase in the electrode potential, as can be seen in Figure 3.

The surface area increase with etching time $t$ can be evaluated from the height evolution of the b-Si pyramids as $h(t)$ [15]. The side walls of the b-Si pyramids have an incline of $\sim 6^{\circ}$ normal to the initial flat surface of Si. The surface area of b-Si can be estimated using a scaling argument by measuring the side-length $x(t)^{2}$, where $x$ is measured from a b-Si cross-section (inset Figure 1a, Figure A2). For example, a linear evolution of the height was established following $h(t) / h(15 \mathrm{~min})=$ $4.5 \times t / 15 \mathrm{~min}$, where $h(15 \mathrm{~min})$ is the height of the pyramids following a $15 \mathrm{~min}$ etch. The side-length of the b-Si cross-section after $t_{1}=15$ min etching was increased by $x(15 \mathrm{~min}) / x(0 \mathrm{~min}) \approx 3.96$, hence the total surface area increase can be estimated as $x^{2} \propto 15.7$ times. For longer etching times $x(t)^{2} \propto \sqrt{h(t) / h\left(t_{1}\right)} x\left(t_{1}\right)^{2}$, where $t_{1}=15 \mathrm{~min}$. After $45 \mathrm{~min}$ etching, $h=900 \mathrm{~nm}$ tall pyramids of b-Si were formed [15] and the surface area was approximately 30 times larger, as compared to the initial flat surface of Si.
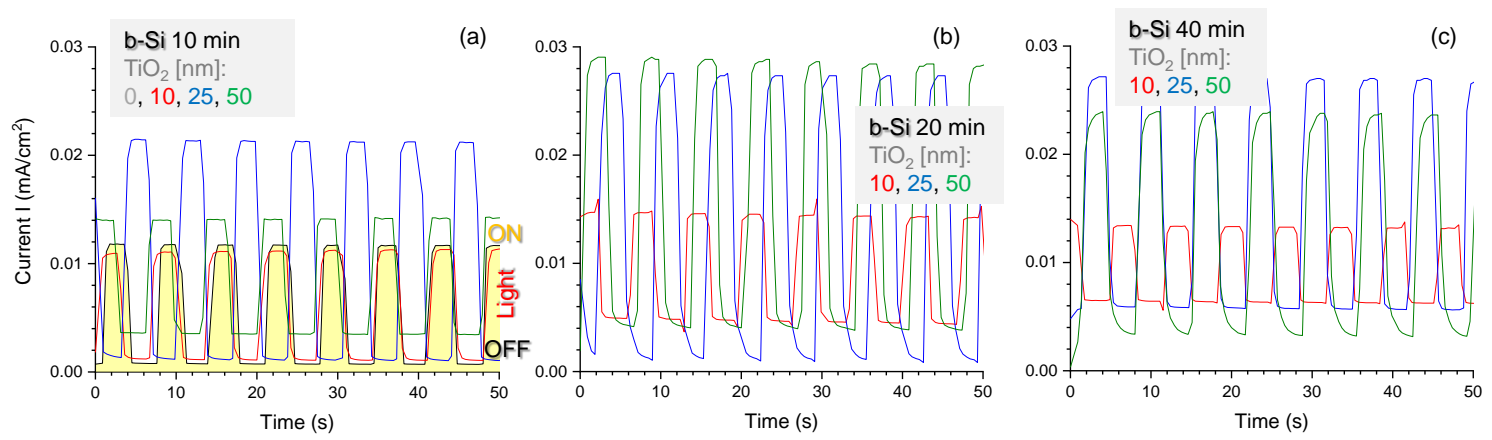

Figure 4. Potentiostatic scan at $1.23 \mathrm{~V}$ vs. RHE for the b-Si photoanodes fabricated for (a) 10, (b) 20 and (c) $40 \mathrm{~min}$ and coated with 10, 25, or $50 \mathrm{~nm} \mathrm{TiO}_{2}$, respectively, in $\mathrm{NaOH}$ electrolyte under chopped light illumination.

(a)

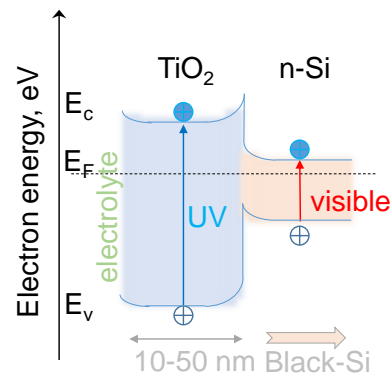

(b)

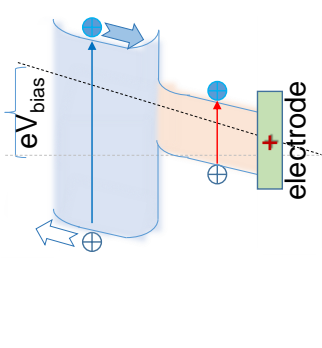

Figure 5. Band diagram of n-n junction between $\mathrm{Si}$ and $\mathrm{TiO}_{2}$ without (a) and with (b) bias. B-Si was fabricated using n-type $\mathrm{Si}$. Under positive bias, holes drift to the titania-solution interface while electrons are drawn into the electrode bulk. The bandgap of $\mathrm{TiO}_{2}$ is $3.1 \mathrm{eV}(400 \mathrm{~nm})$ and $1.12 \mathrm{eV}$ for Si. Under a white light (spectrally broad) illumination, e-h generation occurs at both the materials forming a $\mathrm{TiO}_{2}-\mathrm{Si}$ n-n-junction. Arrows show e,h drift direction. 


\subsection{Black-Si with $\mathrm{TiO}_{2}$ and $\mathrm{CoO}_{x}$ : Potentiostatic and Potentiodynamic Scans}

Semiconductor modification with oxygen/hydrogen evolution (OER/HER) cocatalysts is a common strategy to increase the efficiency of photoelectrochemical water splitting reactions [20]. Cobalt oxide-based materials have demonstrated themselves as a promising candidate for the development of non-noble metal oxygen evolution catalysts. Non-noble metals are of interest to improve the relatively high overpotential and slow kinetics of the OER [21]. In this study, PLD was used to deposit $150 \mathrm{~nm}$ of cobalt oxide $\mathrm{CoO}_{x}$ on b-Si surfaces etched for $20 \mathrm{~min}$ and coated conformally with $10 \mathrm{~nm} \mathrm{TiO}_{2}$ by ALD. The surface morphology of the $\mathrm{CoO}_{x}$ cocatalyst layer on b-Si is shown in Figure 6. The deposition of materials of 10-100 nm thickness over the nano-rough surface of b-Si by different methods (sputtering, e-beam or thermal evaporation) do not normally block the surface and the high surface area and nano-roughness which decreases reflectivity is maintained.

The presence of cobalt oxide crystallites on the surface of $\mathrm{b}-\mathrm{Si} / \mathrm{TiO}_{2}$ spikes is clearly recognizable (Figure 6). It is important to note that the fabrication conditions adopted in this study for the formation of a heterostructured photoelectrode allowed the preservation of the initial morphology of the b-Si substrate, contrary to the case reported in ref. [12], where the top layer of $\mathrm{Co}(\mathrm{OH})_{2}$ was electrodeposited on $\mathrm{b}-\mathrm{Si} / \mathrm{TiO}_{2}(8 \mathrm{~nm})$ blocking large areas of underlying substrate beneath a thick coating.

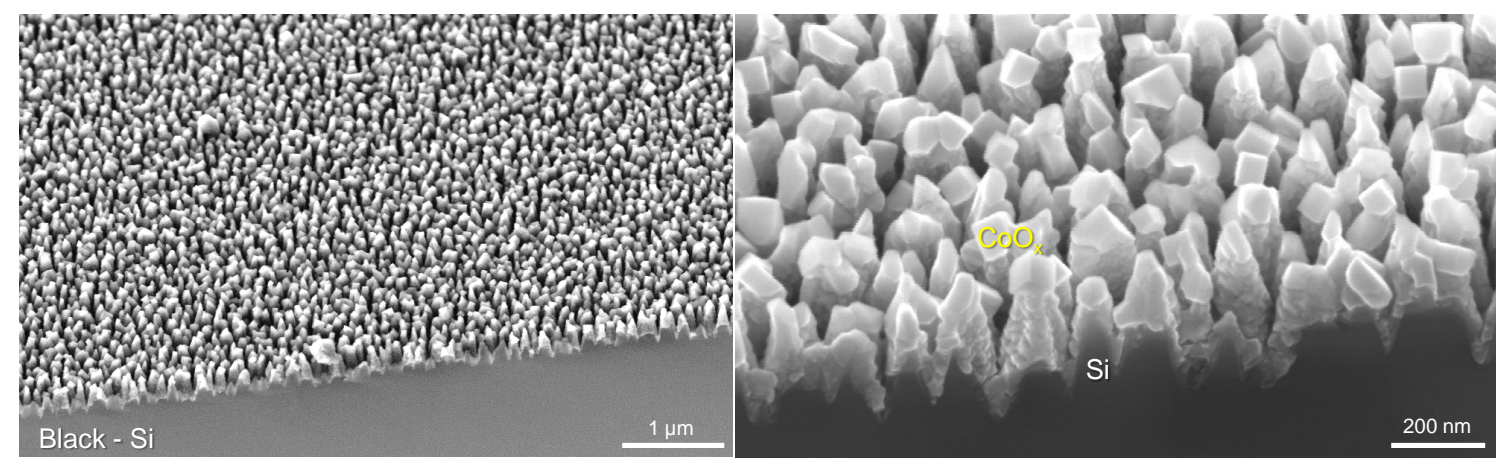

Figure 6. SEM images of as-fabricated b-Si photoanodes etched for $20 \mathrm{~min}$ and coated with $10 \mathrm{~nm} \mathrm{TiO}_{2}$ with addition of $150 \mathrm{~nm} \mathrm{CoO}_{x}$ cocatalyst.

The results of the PEC investigations are summarized in Figure 7 and compared with the response of planar Si photoelectrode with $10 \mathrm{~nm} \mathrm{TiO}_{2}$ coating as well as that of b-Si fabricated for 40 min with $10 \mathrm{~nm} \mathrm{TiO}$. The increase in both dark- and photo-currents in the sequence: planar Si/ $\mathrm{TiO}_{2}(10 \mathrm{~nm})$ $<\mathrm{b}-\mathrm{Si}(20 \mathrm{~min}) / \mathrm{TiO}_{2}(10 \mathrm{~nm})<\mathrm{b}-\mathrm{Si}(40 \mathrm{~min}) / \mathrm{TiO}_{2}(10 \mathrm{~nm})$ should be attributed to an increase in the electrochemically active surface area of the electrode (Figure 7a). It should be noted, however, that an increase in dark currents is more pronounced than that of photocurrents (taken as the difference between the current values in dark and under illumination). Moreover, the increase in both dark- and photo-currents of planar-Si vs. b-Si is not comparable with the increase in surface area of the samples (about 30 times), as discussed above. A possible explanation for this could be the previously discussed energy barrier that forms at the heterojunction between n-type $\mathrm{Si}$ and $\mathrm{TiO}_{2}$ (Figure 5). The deposition of $\mathrm{CoO}_{x}$ leads to a significant increase in photocurrents, especially in the range of lower potential values, i.e., $0.1 \mathrm{~V}<E<1.1 \mathrm{~V}$. This can be attributed to efficient hole-mediated oxidation of water molecules to $\mathrm{O}_{2}$ on the surface of the cobalt oxide cocatalyst.

Chronoamperograms recorded under chopped illumination at the stationary potential of $1.23 \mathrm{~V}$ (Figure $7 \mathrm{~b}$ ) reveal the same general trends described above. A slight decay of the PEC response of $\mathrm{CoO}_{x}$-modified b-Si(20 $\left.\mathrm{min}\right) / \mathrm{TiO}_{2}(10 \mathrm{~nm})$ sample can be observed during the $200 \mathrm{~s}$ long measurement at $1.23 \mathrm{~V}$. This points to some rearrangement of the photoactive layer. SEM micrographs of the photoelectrode following the OER-exploitation in the PEC cell for $30 \mathrm{~min}$ in NaOH electrolyte (Figure 8) reveal drastic changes in the morphology of the sample with the formation of sub-micrometer sized hexagonal crystals randomly distributed all over the surface, characteristic of $\mathrm{Co}(\mathrm{III}) \mathrm{OOH}$ [22], which is 
known to play the role of active site in oxygen evolution reaction [23] and is in agreement with other studies showing the in situ formation of $\mathrm{Co}(\mathrm{III}) \mathrm{OOH}[24,25]$.
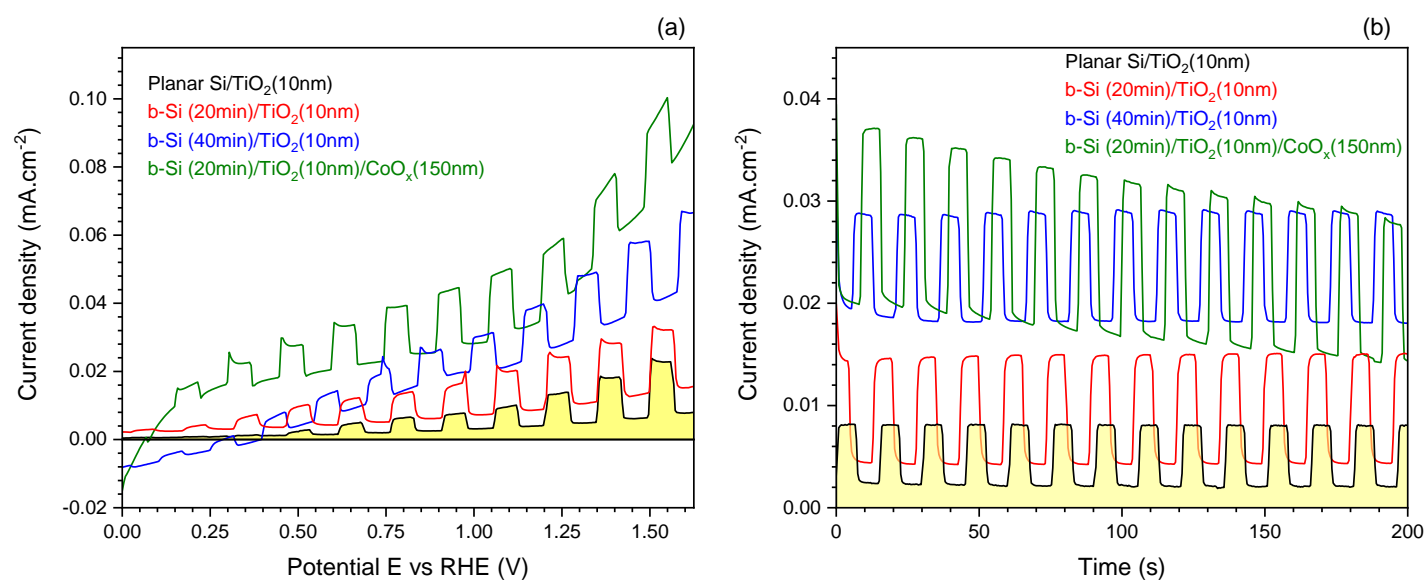

Figure 7. Potentiodynamic (a) and potentiostatic (b) scan at $1.23 \mathrm{~V}$ vs. RHE for the b-Si photoanodes fabricated for 20 and $40 \mathrm{~min}$ and coated with $10 \mathrm{~nm} \mathrm{TiO} 2$ with addition of $150 \mathrm{~nm} \mathrm{CoO} x$ cocatalyst layer in $\mathrm{NaOH}$ electrolyte under chopped light illumination. The potential scan speed was $10 \mathrm{mV} / \mathrm{s}$ and light $\mathrm{ON}-\mathrm{OFF}$ chopping with $\sim 8 \mathrm{~s}$ period in (B).

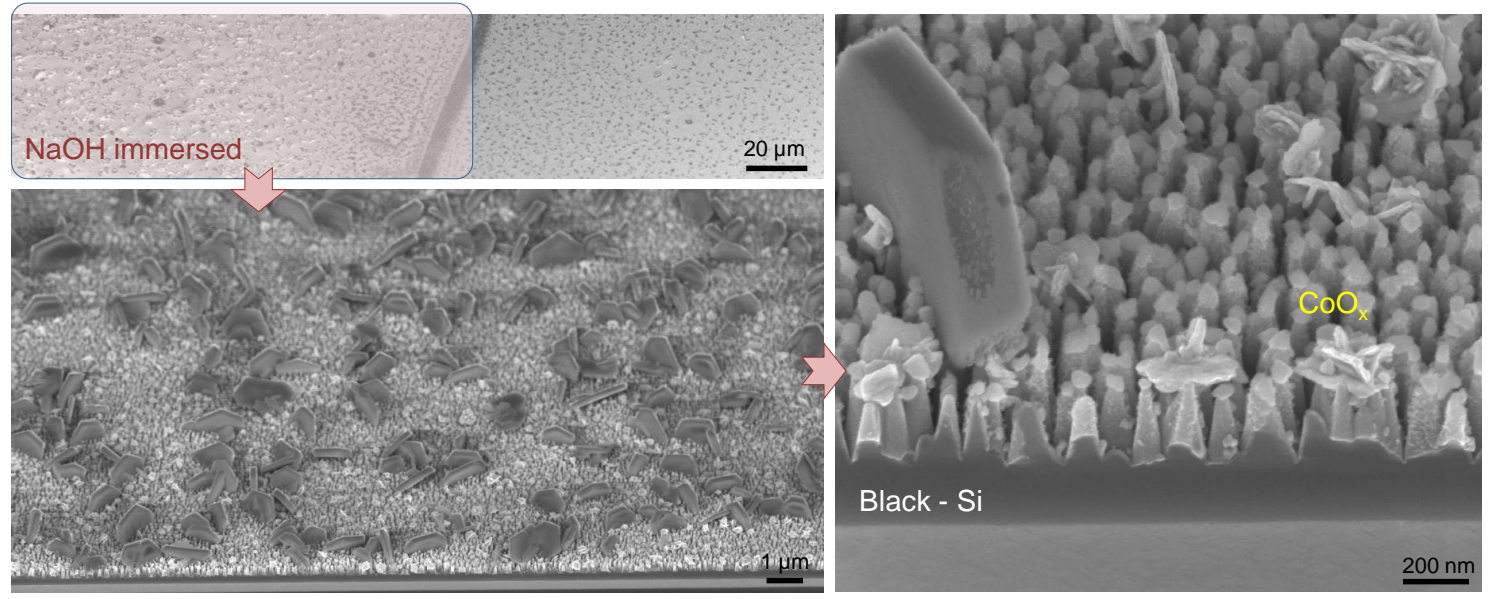

Figure 8. SEM images of b-Si photoanodes etched for 20 min and coated with $10 \mathrm{~nm} \mathrm{TiO}_{2}$ with addition of $150 \mathrm{~nm} \mathrm{CoO}$ cocatalyst after the exploitation for $30 \mathrm{~min}$ in photoelectrochemical cell.

The mechanism of photoelectrocatalytic OER on the surface of $\mathrm{CoO}_{x}$-modified b-Si $(20 \mathrm{~min}) / \mathrm{TiO}_{2}(10 \mathrm{~nm})$ could be as follows: holes photogenerated in $\mathrm{b}-\mathrm{Si} / \mathrm{TiO}_{2}$ drift to the electrode/solution interface, where they are captured by $\mathrm{CoO}_{x}$. This interaction leads to oxidation of active cobalt oxide sites to $\mathrm{Co}(\mathrm{IV})$, the formation of which, during photocatalytic water oxidation, has been previously evidenced [26]. The authors suggested that two sequential hole injections convert the adjacent $\mathrm{Co}(\mathrm{III})-\mathrm{OH}$ groups to $\mathrm{Co}(\mathrm{IV})=\mathrm{O}$ centers. Subsequent addition of the water molecule to one of the oxo sites leads to O-O bond formation, followed by reduction of both cobalt centers to Co(III) and catalyst recovery. Such catalytic oxidation/reduction cycle explains the recrystallization/restructuring of $\mathrm{CoO}_{x}$ layer seen in SEM images of the sample which underwent photoelectrochemical testing (Figure 8). Irrespective of the rearrangement of cocatalyst layer during PEC performance, the spiky morphology of $\mathrm{b}$-Si is retained, which means that ALD-deposited conformal $\mathrm{TiO}_{2}$ coating effectively protects silicon substrate from chemical dissolution in alkaline medium.

When considering the semiconductor/electrocatalyst interface, it is interesting to note that significantly higher photocurrents were reported when $\mathrm{Co}(\mathrm{OH})_{2}$ was electrodeposited on b-Si with $8 \mathrm{~nm} \mathrm{ALD} \mathrm{of} \mathrm{TiO}_{2}$ [12], or when a continuous conformal $50 \mathrm{~nm} \mathrm{CoO}$ layer was deposited via ALD on 
planar n-type $\mathrm{Si}$ with $2 \mathrm{~nm} \mathrm{SiO}_{x}$ [25]. In our work, the coating of b-Si surface with $\mathrm{CoO}_{x}$ via PLD was not sufficiently bulky to cover the substrate with islands of cocatalyst as compared to Yu et al. (2017), where the authors suggested that a large coverage of cocatalyst on the photoanode is kinetically favorable for OER [12]. In contrast, Oh et al. (2019) demonstrated that photoanodes of b-Si with electrodeposited nanoparticles of Ni yielded photocurrents as high as $23 \mathrm{~mA} \mathrm{~cm}^{-2}$ [11]. In the latter case, special care was taken to ensure good electrical contact between $\mathrm{Ni}$ and $\mathrm{Si}$ by electroplating $\mathrm{Ni}$ directly onto freshly hydrogenated b-Si substrate. It is possible that the removal of native $\mathrm{SiO}_{2}$ could improve the photoelectrochemical performance of the nano-heterostructure fabricated herein. Thus, the comparison of results reported on b-Si photoelectrodes is not straightforward, since many aspects have to be considered and taken into account [27], and the understanding of the semiconductor/catalyst interface needs to be advanced in order to properly engineer and optimize the performance of water-splitting devices.

\section{Conclusions and Outlook}

B-Si passivated with $\mathrm{TiO}_{2}$ nano-layers deposited via ALD can be used as photoanodes. Such surfaces can be utilized for the deposition of the co-catalyst of water oxidation to drive OER. Structural characterization of the b-Si photoanodes reveal their nano-roughness which is instrumental for increase of surface area (current density) and reduction of reflectivity $R$ (increase of absorbance $A=1-R-T$ where $T$ is the transmittance). The experiments were carried out at $1.23 \mathrm{~V}$ potential, which is the thermodynamic potential of water oxidation to $\mathrm{O}_{2}$, and could produce larger photo-currents at a larger bias. This is particularly relevant for photoelectrolysis of water on $\mathrm{TiO}_{2}$ [28] (Figure 5) where a strong increase in the OER rate is observed at $1.77 \mathrm{~V}$ [29]. One further improvement of photoanodes based on b-Si could be achieved by the removal of the native $\mathrm{SiO}_{2}$ on $\mathrm{Si}$, which is $\sim 2 \mathrm{~nm}$, by Ar-plasma treatment. Native oxide is known to cause low photo-currents in the photoelectrolysis of water and solar cells [29].

B-Si coated with $\mathrm{TiO}_{2}$ is also a promising biocidal (anti-viral and bactericidal) surface, exhibiting strong oxidizing (electron removal) properties under UV light illumination that can be used to kill attaching microbes. A uniform $\mathrm{TiO}_{2}$ coating of 1-10 nm was not found to change the surface morphology of b-Si (Figure 2) and its bactericidal property is expected to be maintained [2] and augmented with the photo-oxidation capability demonstrated in this work. Furthermore, the photo-oxidation capabilities can be also inferred from numerical simulations of light intensity distribution (Figure A2). A surface coating of a nano-thin layer of $\mathrm{TiO}_{2}$ or $\mathrm{CoO}_{x}$ will cause a stronger absorbance inside the b-Si needles due to to reduced reflectivity (Figures A1 and A2). Thin surface layers can also contribute to a better charge separation and hole transport to the surface where the oxidation of water (by bacteria or virus) is taking place. Wurtzite $\mathrm{CoO}_{x}$ is a p-type semiconductor with strong absorption of photons at $0.7-1.0 \mathrm{eV}$, which is considerably smaller than the direct bandgap energy of $1.6 \mathrm{eV}$ [30]. A photoanode with $\mathrm{CoO}_{x}$ on b-Si would harvest longer wavelengths at the surface while the positive bias of b-Si contribute to e-h separation by electron extraction (see Figure 5). A self-similar 3D fractal Si fabrication with an Hausdorff dimension of $D=2.322$ was demonstrated using anisotropic etching of Si [31] (see Appendix A for the statistical and fractal definitions of AFM scans). Complex fractal 3D geometries with high porosity and surface area with conformal deposition by ALD are very promising for applications in light harvesting and photo-catalysis.

Author Contributions: Conceptualization, D.P.L., S.J., T.L.; experimentation, D.P.L., D.P., J.J., F.H., C.X.; data analysis, D.P.L., F.H., S.J., J.J.; investigation D.P.L., J.H., E.P.I., J.J.; data curation, D.P.L., S.J., J.J.; writing-original draft, D.P.L. and J.J.; writing—review and editing, all authors; project administration, D.P.L., T.L., S.J. All authors have read and agreed to the published version of the manuscript.

Funding: This research was funded by the ARC Discovery DP190103284 and JST CREST JPMJCR19I3 grants. We gratefully acknowledge support from the Swiss National Science Foundation (MARVEL NCCR and project 200021-159198).

Acknowledgments: Support of operational costs of Nanotechnology facility by Swinburne University of Technology 2016-19 is acknowledged. This work was performed in part at the Melbourne Centre for Nanofabrication (MCN) in 
the Victorian Node of the Australian National Fabrication Facility (ANFF).This work was supported in part by the AINSE ANSTO French Embassy (SAAFE) Research Internship Program.

Conflicts of Interest: The authors declare no conflict of interest.

\section{Appendix A}
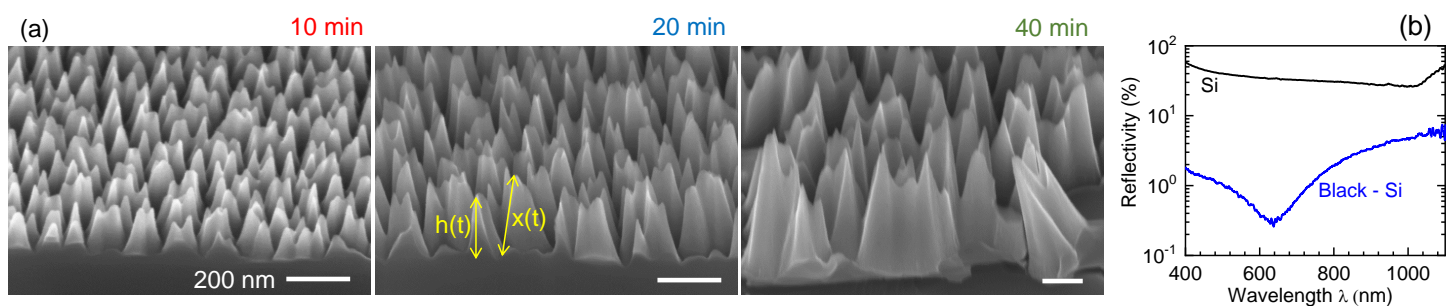

Figure A1. Topography and reflectivity of as-fabricated b-Si. (a) SEM micrographs at $45^{\circ}$ tilt of b-Si etched for 10, 20 and $40 \mathrm{~min}$, respectively. The height $h(t)$ and side-length $x(t)$ of nano-pyramids evolution during etch time $t$ was used to evaluate surface area, see text for details. (b) Reflectivity of b-Si etched for 15 min was $R<1 \%$ over most of visible spectral range. Reflectivity of $\mathrm{Si}$ (100) wafer is shown for reference. Until the bandgap energy $1.12 \mathrm{eV}(\lambda=1107 \mathrm{~nm})$, reflectivity $R=(n-1)^{2} /(n+1)^{2}$ is dominated by the high real part of the refractive index, $n$; for normal incidence in air $n_{a}=1$.

Figure A2 shows the exact numerical solution of Maxwell's equations for the plane wave incidence on b-Si pyramids. For comparison, one of the pyramids (left) is conformally covered by 10-nm-thick walls of $\mathrm{TiO}_{2}$. Even such a thin $\mathrm{TiO}_{2}$ layer acts as an anti-reflection coating and creates higher light intensity $E^{2}$ inside the $\mathrm{Si}$ nano-pyramids. The anti-reflection property of $\mathrm{TiO}_{2}$ would be even more pronounced in water solution $n \approx 1.3$ at visible wavelengths as compared with air $n=1$.

Figure A3 shows the Firestone-Abbott (F-A) bearing curves of $b$-Si etched for different etch times. The F-A curve is the cumulative probability density function of the surface profile's height which is calculated by integrating the profile of the AFM trace. Each curve can be separated into the peak, kernel and valley sections after linear fit (tangential section) of the central part of the bearing ratio (see the marking for the 40 min etched sample). The positions of the minimum and maximum depth/height of the linear section of the AFM scan at intersections at bearing ratios of 0 and $100 \%$, respectively, defines the kernel Section (209 and $446 \mathrm{~nm}$ in Figure A3). At those depth (height) values, the actual bearing ratios reads $M_{r 1}=8 \%$ and $M_{r 2}=92 \%$, which are the mass ratios (DIN4776 standard). The area below the F-A curve, up to the point $M_{r 1}$, represent the mass (an integral) of the most protruding peaks of surface roughness (the peaks region). The mass ratio point $M_{r 2}$ defines the point, which excludes the mass of the most deep valleys (the valleys region). The kernel roughness depth $R_{k}$ is the thickness of the kernel at the flattest part of the bearing curve with the largest increase of material under the bearing curve. The reduced peak height $R_{p k}$ and the reduced valley depth $R_{v k}$ corresponds to the thickness of the bearing curve above (below) the central kernel profile, respectively. These parameters can be defined for surfaces etched for different times (Figure A3) and lay the foundation for statistical analysis of different surfaces.

The depth (height) profile is self-similar when roughness is investigated at different scales, hence is self-affine [32]. The Weierstrass-Mandelbrot (W-M) function is used for characterization of the height profile $z(x)$ along scan in $\mathrm{x}$-direction. The $\mathrm{W}-\mathrm{M}$ function has a fractal dimension, $D$ [32]:

$$
z(x)=G^{(D-1)} \sum_{n=n_{l}}^{\infty} \frac{\cos \left(2 \pi \gamma^{n} x\right)}{\gamma^{n(2-D)}} ; 1<D<2 ; \gamma>1
$$

where $G$ is a scaling constant, $\gamma^{n} \equiv 1 / \lambda_{n}$ is the frequency mode corresponding to the reciprocal of roughness wavelength $\lambda_{n}$; the low cut-off frequency is defined by the length $L$ (AFM scan length here) as $\gamma^{n_{l}}=1 / L$. The fractal dimension $D=\frac{\log N}{\log m}$, where $m$ is the magnification and $N$ is the number of 
self-similar segments $1 / m$, which form a line of unity length under magnification $m((1 / m) \times m=1)$; a one-dimensional linear segment is considered here as an example).

The fractal dimension $D$ can be found from the power spectrum of $z(x)$, which is superimposed of infinite number of frequency modes and defines the amplitude of the roughness profile at different scales (AFM profile is considered here) [32]:

$$
S(\omega)=\frac{G^{2(D-1)}}{2 \ln \gamma} \cdot \frac{1}{\omega^{(5-2 D)}} .
$$

If the power spectrum $S(\omega)$ is known, it is possible to calculate statistical parameters of the surface: the variances of the height, the slope and the curvature at different frequencies.

Another practical method to define the fractal dimension is based on the auto-correlation of AFM image (trace) [33]: $R(m, n)$ where $m, n$ are integers describing a shift in $\mathrm{x}$ and $\mathrm{y}$-directions, respectively, of the original image $z(x, y)$ which is made in $N$ data acquisition steps. Then the structure function is defined as $S(m, n)=2 S_{q}^{2}(1-R(m, n))$, where $S_{q}$ is the root mean square roughness. Then the structure function of a self-similar pattern along the chosen direction $\tau$ follows $S(\tau)=K \tau^{2(2-D)}$ law [33], where $K$ is the pseudo-topothesy (defines the absolute amplitude of spatial frequencies) and $D$ is the fractal dimension. Nanoscale self-similar surface roughness from $20 \mathrm{~nm}$ to $300 \mathrm{~nm}$ ( $\min$-max height) was demonstrated on a thermally rescalled polystyrene coated with gold [34]. By changing scale of SEM images, self-similarity and fractal nature of such surfaces was evidenced.

The box-counting method applied to AFM or SEM images is one of the simplest ways to estimate fractal dimension [35]. The number of boxes $N(r) \propto r^{-D}$ of size $r$ required to cover a chosen feature in the image provides direct estimate of the fractal dimension $D$ from the slope when log-log plot is made $N(r)$ vs. $r$. A systematic structure analysis by bearing ratio and fractal dimension of nanostructures is urgently required for understanding their link with the biocidal (anti-viral and antibacterial) properties of such surfaces, e.g., b-Si [2].

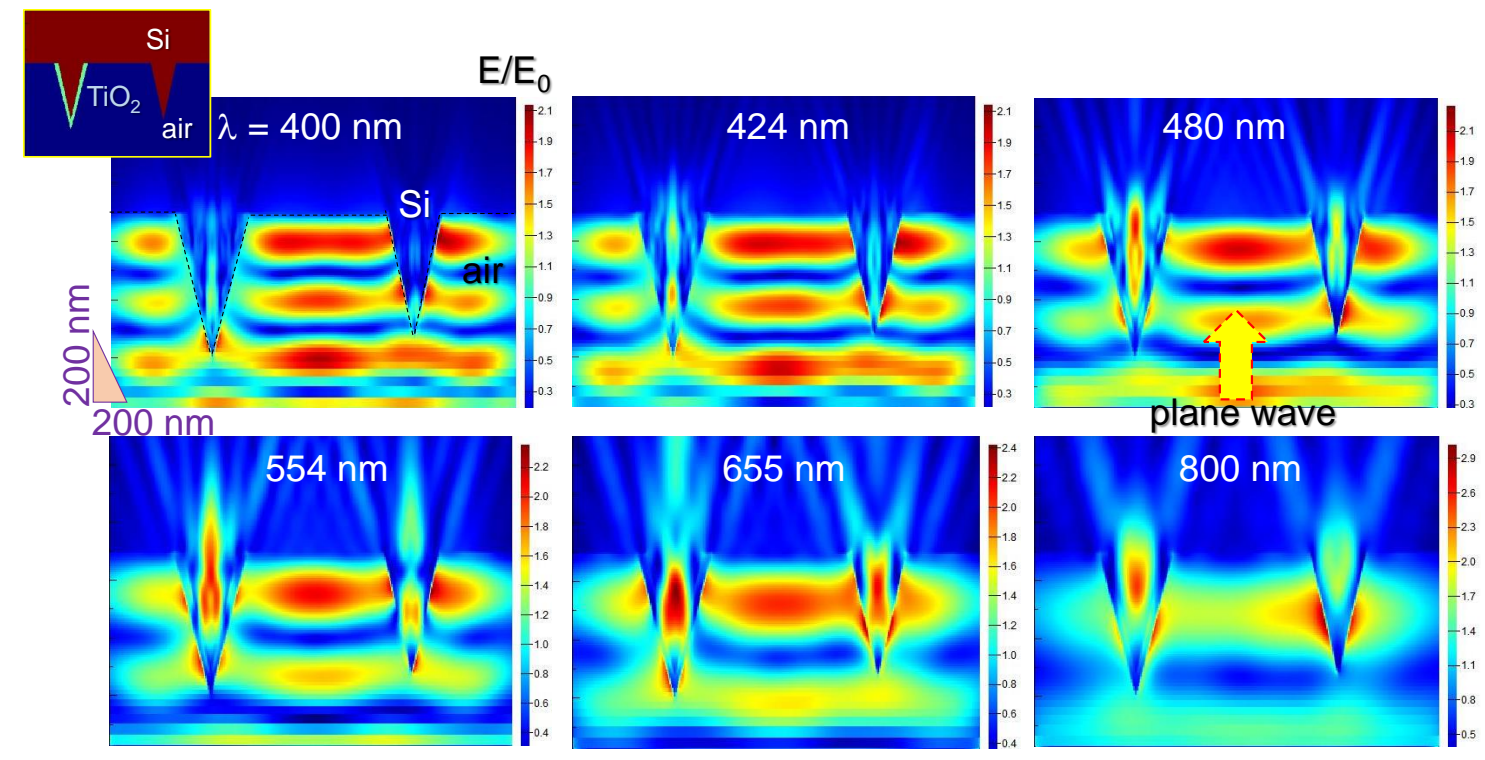

Figure A2. Finite differences time domain (FDTD) simulations (Lumerical) of light intensity distribution on b-Si pyramids with $10 \mathrm{~nm} \mathrm{TiO}{ }_{2}$ coating and without at different wavelengths $\lambda$. The inset shows the refractive index cross section where $\mathrm{TiO}_{2}$ is modelled by $n=2.5$ for all the wavelength while refractive index of $\mathrm{Si}$ was taken from the Lumerical data base with real and imaginary parts $\tilde{n}(\lambda)=n(\lambda)+i \kappa(\lambda)$. The E-field is polarised in the plane of incidence and $E_{0}=1$. 


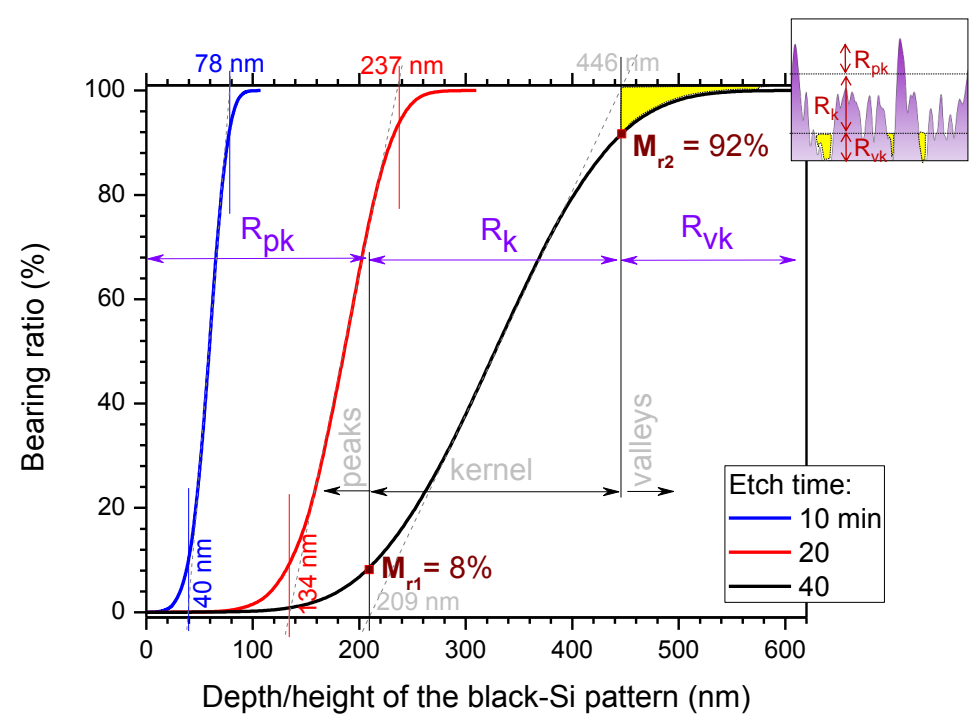

Figure A3. Bearing ratios of AFM traces (Figure 1b,c) of b-Si etched for 10, 20 and $40 \mathrm{~min}$. See text for definitions of the parameters marked on the the Firestone-Abbott bearing curve (standards DIN4776; STN ISO 13 565-2). Inset illustrates schematically the peak, kernel, and valley extent on actual AFM profile of 40 min etched Black-Si; yellow area-mark corresponds to the air pockets in the b-Si pattern which have height (depth) extent of $R_{v k}$.

\section{References}

1. Jansen, H.; de Boer, M.; Legtenberg, R.; Elwenspoek, M. The black silicon method: A universal method for determining the parameter setting of a fluorine-based reactive ion etcher in deep silicon trench etching with profile control. J. Micromech. Microeng. 1995, 5, 115. [CrossRef]

2. Ivanova, E.P.; Hasan, J.; Webb, H.K.; Gervinskas, G.; Juodkazis, S.; Truong, V.K.; Wu, A.H.F.; Lamb, R.N.; Baulin, V.; Watson, G.S.; et al. Bactericidal activity of nanostructured black silicon. Nat. Commun. 2013, 4, 2838. [CrossRef] [PubMed]

3. Pham, V.T.H.; Truong, V.K.; Mainwaring, D.; Guo, Y.; Baulin, V.; Kobaisi, M.A.; Gervinskas, G.; Juodkazis, S.; Zeng, W.R.; Doran, P.; et al. Nanotopography as a trigger for the microscale, autogenous and passive lysis of erythrocytes. J. Mater. Chem. B 2014, 2, 2819-2826. [CrossRef] [PubMed]

4. Langer, C.; Prommesberger, C.; Ławrowski, R.; Schreiner, R.; Serbun, P.; Müller, G.; Düsberg, F.; Hofmann, M.; Bachmann, M.; Pahlke, A. Field emission properties of p-type black silicon on pillar structures. J. Vac. Sci. Technol. B 2020, 34, 02G107. [CrossRef]

5. Seniutinas, G.; Gervinskas, G.; Verma, R.; Gupta, B.D.; Lapierre, F.; Stoddart, P.R.; Clark, F.; McArthur, S.L.; Juodkazis, S. Versatile SERS sensing based on black silicon. Opt. Express 2015, 23, 6763-6772. [CrossRef]

6. Ščajev, P.; Malinauskas, T.; Seniutinas, G.; Arnold, M.D.; Gentle, A.; Aharonovich, I.; Gervinskas, G.; Michaux, P.; Hartley, J.S.; Mayes, E.L.H.; et al. Light-induced reflectivity transients in black-Si nanoneedles. Sol. Energy Mater. Sol. Cells 2016, 144, 221-227. [CrossRef]

7. Nishijima, Y.; Komatsu, R.; Ota, S.; Seniutinas, G.; Balčytis, A.; Juodkazis, S. Anti-reflective surfaces: Cascading nano/microstructuring. Appl. Phys. Lett. Photonics 2016, 1, 076104. [CrossRef]

8. Shoji, T.; Mototsuji, A.; Balcytis, A.; Linklater, D.; Juodkazis, S.; Tsuboi, Y. Optical tweezing and binding at high irradiation powers on black-Si. Sci. Rep. 2017, 7, 12298. [CrossRef]

9. Pekarek, R.T.; Christensen, S.T.; Liu, J.; Neale, N.R. Energetic Effects of Hybrid Organic/Inorganic Interfacial Architecture on Nanoporous Black Silicon Photoelectrodes. Sustain. Energy Fuels 2019, 3, 1600-1667. [CrossRef]

10. Yang, F.; Aguiar, J.A.; Fairchild, M.; Vakki, W.; Younan, S.; Zhou, Y.; Zhuo, L.; Gu, J. Dual Protection Layer Strategy to Increase Photoelectrode-Catalyst Interfacial Stability: A Case Study on Black Silicon Photoelectrodes. Adv. Mater. Interfaces 2019, 6, 1802085. [CrossRef] 
11. Oh, K.; Joanny, L.; Gouttefangeas, F.; Fabre, B.; Dorcet, V.; Lassalle-Kaiser, B.; Vacher, A.; Meriadec, C.; Ababou-Girard, S.; Loget, G. Black Silicon Photoanodes Entirely Prepared with Abundant Materials by Low-Cost Wet Methods. ACS Appl. Energy Mater. 2019, 2, 1006-1010. [CrossRef]

12. Yu, Y.; Zhang, Z.; Yin, X.; Kvit, A.; Liao, Q.; Kang, Z.; Yan, X.; Zhang, Y.; Wang, X. Enhanced photoelectrochemical efficiency and stability using a conformal TiO2 film on a black silicon photoanode. Nat. Energy 2017, 2, 17045. [CrossRef]

13. Yao, X.; Schneider, C.W.; Lippert, T.; Wokaun, A. Manipulation of ion energies in pulsed laser deposition to improve film growth. Appl. Phys. A 2019, 125, 344. [CrossRef]

14. Gervinskas, G.; Seniutinas, G.; Hartley, J.S.; Kandasamy, S.; Stoddart, P.R.; Fahim, N.F.; Juodkazis, S. Surface-enhanced Raman scattering sensing on black silicon. Ann. Der Phys. 2013, 525, 907-914. [CrossRef]

15. Balčytis, A.; Ryu, M.; Seniutinas, G.; Nishijima, Y.; Hikima, Y.; Zamengo, M. Si-based infrared optical filters. Opt. Eng. 2015, 54, 127103-127103. [CrossRef]

16. Buividas, R.; Fahim, N.; Juodkazytè, J.; Juodkazis, S. Novel method to determine the actual surface area of a laser-nanotextured sensor. Appl. Phys. A 2013, 14, 169-175. [CrossRef]

17. Juodkazis, K.; Juodkazytè, J.; Šebeka, B.; Savickaja, I.; Juodkazis, S. Photoelectrochemistry of silicon in HF solution. J. Solid State Electrochem. 2013, 17, 2269-2276. [CrossRef]

18. Brack, P.; Dann, S.E.; Wijayantha, K.; Adcock, P.; Foster, S. An assessment of the viability of hydrogen generation from the reaction of silicon powder and sodium hydroxide solution for portable applications. Int. J. Energy Res. 2017, 41, 220-228. [CrossRef]

19. Mizeikis, V.; Kowalska, E.; Juodkazis, S. Resonant localization, enhancement, and polarization. In Nanoplasmonics: Advanced Device Applications; Chon, J.W.M., Iniewski, K., Eds.; CRC Press: Boca Raton, FL, USA, 2009; pp. 126-134.

20. Si, W.; Pergolesi, D.; Haydous, F.; Fluri, A.; Wokaun, A.; Lippert, T. Investigating the behavior of various cocatalysts on $\mathrm{LaTaON}_{2}$ photoanode for visible light water splitting. Phys. Chem. Chem. Phys. 2017, 19, 656-662. [CrossRef]

21. Deng, X.; Tüysüz, H. Cobalt-Oxide-Based Materials as Water Oxidation Catalyst: Recent Progress and Challenges. ACS Catal. 2014, 4, 3701-3714. [CrossRef]

22. Yang, J.; Liu, H.; Martens, W.N.; Frost, R.L. Synthesis and Characterization of Cobalt Hydroxide, Cobalt Oxyhydroxide, and Cobalt Oxide Nanodiscs. J. Phys. Chem. C 2010, 114, 111-119. [CrossRef]

23. Stevens, M.; Kast, M.; Trotochaud, L.; Smith, A.; Boettcher, S. Cobalt-Iron (Oxy)hydroxide Oxygen Evolution Electrocatalysts: The Role of Structure and Composition on Activity, Stability, and Mechanism. J. Am. Chem. Soc. 2015, 137, 10.1021/jacs.5b00281.

24. Weidler, N.; Paulus, S.; Schuch, J.; Klett, J.; Hoch, S.; Stenner, P.; Maljusch, A.; Brötz, J.; Wittich, C.; Kaisera, B.; et al. CoOx thin film deposited by CVD as efficient water oxidation catalyst: Change of oxidation state in XPS and its correlation to electrochemical activity. Phys. Chem. Chem. Phys. 2016, 18, 10708-10718. [CrossRef] [PubMed]

25. Zhou, X.; Liu, R.; Sun, K.; Papadantonakis, K.M.; Brunschwig, B.S.; Lewis, N.S. $570 \mathrm{mV}$ photovoltage, stabilized $\mathrm{n}-\mathrm{Si} / \mathrm{CoOx}$ heterojunction photoanodes fabricated using atomic layer deposition. Energy Environ. Sci. 2016, 9, 892-897. [CrossRef]

26. Zhang, M.; de Respinis, M.; Frei, H. Time-resolved observations of water oxidation intermediates on a cobalt oxide nanoparticle catalyst. Nat. Chem 2014, 6, 362-367. [CrossRef] [PubMed]

27. Nellist, M.R.; Laskowski, F.A.L.; Lin, F.; Mills, T.J.; Boettcher, S.W. Semiconductor-Electrocatalyst Interfaces: Theory, Experiment, and Applications in Photoelectrochemical Water Splitting. Acc. Chem. Res. 2016, 49, 733-740. [CrossRef]

28. Juodkazis, K.; Juodkazytė, J.; Kalinauskas, P.; Jelmakas, E.; Juodkazis, S. Photoelectrolysis of Water: Solar Hydrogen-Achievements and Perspectives. Opt. Express Energy Express 2010, 18, A147-A160. [CrossRef]

29. Juodkazytė, J.; Seniutinas, G.; Šebeka, B.; Savickaja, I.; Malinauskas, T.; Badokas, K.; Juodkazis, K.; Juodkazis, S. Solar water splitting: Efficiency discussion. Int. J. Hydrogen Energy 2016, 41, 11941-11948. [CrossRef]

30. Wang, Y.; Ge, H.X.; Chen, Y.P.; Meng, X.Y.; Ghanbaja, J.; Horwat, D.; Pierson, J.F. Wurtzite CoO: A direct band gap oxide suitable for a photovoltaic absorber. Chem. Commun. 2018, 54, 13949-13952. [CrossRef]

31. Berenschot, E.; Jansen, H.V.; Tas, N.R. Fabrication of 3D fractal structures using nanoscale anisotropic etching of single crystalline silicon. J. Micromech. Microeng. 2013, 23, 055024. [CrossRef] 
32. Majumdar, A.; Bhushan, B. Role of Fractal Geometry in Roughness Characterization and Contact Mechanics of Surfaces. J. Tribol. 1990, 112, $205-216$. [CrossRef]

33. Ţalu, Ş.; Bramowicz, M.; Kulesza, S.; Pignatelli, F.; Salerno, M. Surface Morphology Analysis of Composite Thin Films based on Titanium-Dioxide Nanoparticles. Acta Phys. Pol. 2017, 131, 1529-1533. [CrossRef]

34. Balcytis, A.; Ryu, M.; Seniutinas, G.; Stoddart, P.R.; Mamun, M.; Morikawa, J.; Juodkazis, S. Nano-rescaling of gold films on polystyrene: Thermal management for SERS. Nanoscale 2017, 9, 690-695. [CrossRef] [PubMed]

35. Nonomura, Y.; Seino, E.; Abe, S.; Mayama, H. Preparation and Characterization of Fractal Elastomer Surfaces. J. Oleo Sci. 2013, 62, 587-590. [CrossRef]

(C) 2020 by the authors. Licensee MDPI, Basel, Switzerland. This article is an open access article distributed under the terms and conditions of the Creative Commons Attribution (CC BY) license (http://creativecommons.org/licenses/by/4.0/). 